\title{
EDITORIAL
}

\section{Assessment of respiratory muscle strength in motor neurone disease: is asking enough?}

\author{
P. Murphy*, R. Lyall ${ }^{\top}$, N. Hart" ${ }^{\#}$ and M.I. Polkey ${ }^{+}$
}

M otor neurone disease (MND), also known as amyotrophic lateral sclerosis (ALS), is a progressive degenerative neuromuscular disease against which the only licensed drug, Riluzole (Rilutek; Sanofi-Aventis, Paris, France), is only partially effective. When respiratory muscle weakness is sufficiently severe, type-II respiratory failure occurs. Several data suggest that noninvasive ventilation (NIV) improves quality of life and, at least in nonbulbar patients, extends life [1-3]. The timing of initiation of NIV requires considerable clinical skill. As the therapy involves hospital attendance, whether or not the patient is admitted [4], it erodes the limited amount of "quality time" the patient has remaining. If administered too early the burdens of the treatment (i.e. the need to use a mask, its associated complications and increased carer dependence) may outweigh the perceived benefits, in that symptoms of sleep-disordered breathing (SDB) may initially be mild. Evidence from Duchene muscular dystrophy suggests that if used too early, negative initial experience may deter patients from using the therapy when they are more symptomatic and/or in ventilatory failure [5]. However, if administered too late the patient may experience unplanned deterioration, which carries the risk of either intubation or poorly managed end-of-life care [6]. The most appropriate method of screening for respiratory failure in these patients with a high pre-test probability remains unclear. The ideal test would be noninvasive, simple to perform and simple to interpret allowing the nonrespiratory specialist, especially neurologists or specialist nurses, to easily adopt the test in an out-patient setting. Most physicians would agree that a trial of NIV should be offered to patients with daytime hypercapnia. However, the onset of daytime hypercapnia in MND can be a relatively late event and introducing a new intervention may be difficult. Studies carried out by STAMBLER et al. [7] and HADJIKOUTIS et al. [8] showed a mean (range) survival of 10 (2.5-24) weeks from onset of detection of daytime hypercapnia to death. Thus the question arises of how best to predict nocturnal hypercapnia [9]. One solution is simply to conduct a sleep study; however, the availability of sleep studies is limited and the test is time consuming for the

\footnotetext{
*Lane Fox Respiratory Unit, Guy's \& St Thomas' NHS Foundation Trust, ${ }^{\#}$ National Institute for Health Research Comprehensive Biomedical Research Centre, Guy's \& St Thomas' NHS Foundation Trust and King's College London, "Dept of Respiratory Medicine, Kings College Hospital, and +Royal Brompton and Imperial College Respiratory Biomedical Research Unit, London, UK.
}

CORRESPONDENCE: M.I. Polkey, Sleep and Ventilation Unit, National Heart and Lung Institute, Royal Brompton Hospital, Sydney Street, London, SW3 6NP, UK. E-mail: m.polkey@rbht.nhs.uk patient, thus, the ability to direct these resources to those most likely to have SDB would be valuable.

Vital capacity is one easy marker of inspiratory muscle weakness with a fall of $>20 \%$ in the supine position being abnormal [10]; however, this marker is nonlinear [11] and less predictive of SDB than direct measurement of inspiratory muscle strength [9].

Whilst detailed studies of respiratory muscle function require invasive techniques [12], and consequently special equipment and expertise, more limited tests such as maximum inspiratory pressure and sniff nasal inspiratory pressure (SNIP) can be performed at the bedside using simple handheld devices. The widespread use of the latter test has greatly improved the accessibility to some forms of respiratory muscle strength assessment in nonspecialist clinics. The wide normal ranges [13] and volitional nature of the tests available to most clinicians necessitate that the results be interpreted appropriately, with a range of tests being required in order to confidently exclude weakness in an individual patient [14]. Nevertheless, the SNIP in particular is a reliable predictor of outcome in MND [15]. SNIP is related to daytime hypercapnia $[9,16]$ and tracks disease progression [17].

In this issue of the European Respiratory Journal, JusT et al. [18] go further, potentially reducing the need to measure strength at all, by reporting on the use of the Borg score in the upright and supine positions (uBORG and sBORG, respectively) for the assessment of respiratory muscle strength in patients with ALS. The use of such a simple screening test has obvious appeal. The test relies on the adverse physiological changes that occur when patients with inspiratory muscle weakness move from an upright to a supine position and increase the load on the respiratory system producing orthopnea. The sBORG score was compared with measures of respiratory muscle function in a population of ALS patients without coexistent cardiorespiratory disease. In keeping with known physiology, JUst et al. [18] demonstrated that patients with an increase in Borg score from the upright to supine position had significantly lower volitional (SNIP $41.7 \pm 21$ versus $63.5 \pm 21 \%$ predicted) and nonvolitional (twitch mouth pressure $6.2 \pm 5$ versus $8.7 \pm 5 \mathrm{cmH}_{2} \mathrm{O}$ ) measures of respiratory muscle strength than patients with no change in dyspnoea.

The study by JusT et al. [18] shows that the SBORG score was a better predictor of severe respiratory muscle weakness, as defined by SNIP $\leqslant 40 \mathrm{cmH}_{2} \mathrm{O}$, than vital capacity obtained while sitting with a sensitivity of $80 \%$ and specificity of $78 \%$ 
using an sBORG score of $\geqslant 3$ compared with a sensitivity of $60 \%$ and specificity of $95 \%$ for a vital capacity $<50 \%$ predicted. The change over time of the sBORG score reflected that of SNIP with declining values for respiratory muscle strength and increasing dyspnoea. The ability to predict sleep SDB was, however, more limited. Although patients with an sBORG score $\geqslant 3$ had a greater proportion of sleep time with arterial oxygen saturation $<92 \%(23 \pm 32$ versus $6.2 \pm 10 ; \mathrm{p}=0.01)$ than those with an sBORG score $<3$, the relationship between this index and $\mathrm{sBORG}$, or indeed measures of respiratory muscle strength, was weak. sBORG was also not able to distinguish daytime hypercapnia from eucapnia although, as one would expect, sBORG was higher in those with hypercapnia. The study utilised nocturnal oximetry rather than either limited or full polysomnography or transcutaneous capnometry and so a relationship with nocturnal hypoventilation may have been missed. Overall, while the study by Just et al. [18] confirms the limited value of lung volumes as a surrogate marker of respiratory muscle strength and suggests a possible role for the use of patient reported upright and supine Borg score in the clinic assessment of patients with ALS, it does not, in our view, justify discarding SNIP, which could be more widely used by medical staff and paramedics with a background in neurology than is presently the case. An important disadvantage of the sBORG, as reported herein, is the need to physically move the patient into the supine position to complete the score which is potentially more time consuming than measuring the SNIP.

Future studies should compare the self-reported sBORG with the SNIP in the prediction of nocturnal hypercapnia and/or ventilator free survival, but at this stage a simple enquiry for the presence of orthopnea can certainly be justified by the data from the study by JusT et al. [18]. Indeed it suggests that this should be incorporated into all neurological reviews of patients with potential for developing SDB and/or ventilatory failure. A positive response to the presence of orthopnoea should prompt assessment of muscle strength with at least a SNIP but we recommend, on the basis of the current data, that those centres already applying SNIP should continue to do so.

\section{STATEMENT OF INTEREST}

Statements of interest for P. Murphy, N. Hart and M.I. Polkey can be found at www.erj.ersjournals.com/misc/statements.dtl

\section{REFERENCES}

1 Bourke SC, Tomlinson M, Williams TL, et al. Effects of noninvasive ventilation on survival and quality of life in patients with amyotrophic lateral sclerosis: a randomised controlled trial. Lancet Neurol 2006; 5: 140-147.

2 Lyall RA, Donaldson N, Fleming T, et al. A prospective study of quality of life in ALS patients treated with noninvasive ventilation. Neurology 2001; 57: 153-156.

3 Mustfa N, Walsh E, Bryant V, et al. The effect of noninvasive ventilation on ALS patients and their caregivers. Neurology 2006; 66: 1211-1217.

4 Chatwin M, Nickol AH, Morrell MJ, et al. Randomised trial of inpatient versus outpatient initiation of home mechanical ventilation in patients with nocturnal hypoventilation. Respir Med 2008; 102: 1528-1535.

5 Raphaël JC, Chevret S, Chastang C, et al. Randomised trial of preventive nasal ventilation in Duchenne muscular dystrophy. Lancet 1994; 343: 1600-1604.

6 Ward S, Chatwin M, Heather S, et al. Randomised controlled trial of non-invasive ventilation (NIV) for nocturnal hypoventilation in neuromuscular and chest wall disease patients with daytime normocapnia. Thorax 2005; 60: 1019-1024.

7 Stambler N, Charatan M, Cedarbaum JM. Prognostic indicators of survival in ALS. ALS CNTF Treatment Study Group. Neurology 1998; 50: 66-72.

8 Hadjikoutis S, Wiles CM. Respiratory complications related to bulbar dysfunction in motor neuron disease. Acta Neurol Scand 2001; 103: 207-213.

9 Lyall RA, Donaldson N, Polkey MI, et al. Respiratory muscle strength and ventilatory failure in amyotrophic lateral sclerosis. Brain 2001; 124: 2000-2013.

10 Allen SM, Hunt B, Green M. Fall in vital capacity with posture. Br J Dis Chest 1985; 79: 267-271.

11 DeTroyer A, Borenstein S, Cordier R. Analysis of volume restriction in patients with respiratory muscle weakness. Thorax 1980; 35: 603-610.

12 Man WD, Moxham J, Polkey MI. Magnetic stimulation for the measurement of respiratory and skeletal muscle function. Eur Respir J 2004; 24: 846-860.

13 Uldry C, Fitting J-W. Maximal values of sniff nasal inspiratory pressures in healthy subjects. Thorax 1995; 50: 371-375.

14 Steier J, Kaul S, Seymour J, et al. The value of multiple tests of respiratory muscle strength. Thorax 2007; 62: 975-980.

15 Morgan RK, McNally S, Alexander M, et al. Use of sniff nasalinspiratory force to predict survival in amyotrophic lateral sclerosis. Am J Respir Crit Care Med 2005; 171: 269-274.

16 Chaudri MB, Liu C, Watson L, et al. Sniff nasal inspiratory pressure as a marker of respiratory function in motor neuron disease. Eur Respir J 2000; 15: 539-542.

17 Fitting JW, Paillex R, Hirt L, et al. Sniff nasal pressure: a sensitive respiratory test to assess progression of amyotrophic lateral sclerosis. Ann Neurol 1999; 46: 887-893.

18 Just N, Bautin N, Danel-Brunaud V, et al. The Borg dyspnoea score: a relevant clinical marker of inspiratory muscle weakness in amyotrophic lateral sclerosis. Eur Respir J 2010; 35: 353-360. 